\title{
A relativização da soberania em prol dos direitos humanos
}

The relativization of sovereignty in favor human rights

\author{
Maria Carolina Florentino Lascala ${ }^{1}$
}

\section{Resumo}

0 presente estudo analisa o novo conceito de soberania que se formou com a afirmação dos direitos humanos na comunidade internacional. 0 surgimento de Cortes internacionais como mecanismo de controle dos tratados assinados em prol desses direitos mostrou-se um fator importante para essa evolução. Assim, o cumprimento das sentenças internacionais pelo Estado Brasileiro confere efetividade aos direitos humanos e, para tanto, deve-se buscar a forma mais adequada à Constituição Federal.

Palavras Chave: Soberania; Sentença internacional; Direitos humanos.

\section{Abstract}

The purpose of this paper is to analyze the new concept of sovereignty which has been formed with the affirmation of human rights in the international community. The creation of international courts as a mechanism of control of the treaties signed to promote human rights proved to be an important factor in this evolution. It will be studied the implementation of those international sentences by the Brazilian State, seeking an adequacy to the Federal Constitution.

Keywords: Sovereignt; . International sentence; Human rights.

\section{Introdução}

A ordem mundial formada após as grandes guerras e a globalização trouxeram um novo conceito de soberania, não mais baseado no clássico "poder absoluto e ilimitado do Estado", mas que sofreu adequações frente às mudanças históricas e sociais dos últimos tempos, concluindo pela prevalência da dignidade humana independentemente de fronteiras territoriais.

\footnotetext{
${ }^{1}$ M estranda em Direito Público pela UNESP. Especialista em Direito Constitucional pela UNISUL. Especialista em Direito Processual pela UNISUL. Graduação em Direito pela USP. Advogada da União. E-mail: carollascala@hotmail.com
} 
Considerando não haver perspectivas de desaparecimento dos Estados (DALLARI, 2007, p. XI), é útil, para os que se dispõem a trabalhar pela consecução de uma ordem política e social justa, reconhecer o Estado atual qualitativamente diferente daquele criado no século XVI.

Planejar o progresso e o bem-estar é condição indispensável para que a humanidade possa viver em paz (DALLARI, 2007, p. 192). Assim, a postura adotada pelos últimos governos brasileiros tem sido a de buscar uma posição de destaque do Brasil na comunidade internacional como uma nação pacífica, de economia próspera e que respeita os direitos humanos e a democracia.

Portanto, um país com tantas perspectivas positivas deve estar apto a acatar as condenações impostas pelas Cortes internacionais protetoras dos direitos humanos e cumpri-las, justamente porque prega a dignidade humana como fundamento desta República.

\section{Histórico e conceito de soberania}

É conveniente fazer algumas considerações sobre o momento histórico em que os Estados soberanos se uniram na comunidade internacional em prol da manutenção da paz e da preservação da raça humana.

Para que isso fosse possível ocorrer, foi preciso reformular o conceito clássico de soberania, que de poder absoluto passou a ser limitado pelo princípio da dignidade humana.

Em verdade, encontrar o conceito exato da expressão "soberania" é um desafio ao estudioso do Direito Constitucional e do Direito Internacional. Ora é tomada como sinônimo de "autonomia", ora como sinônimo de "independência", mas sempre associada ao Estado.

O termo foi empregado por séculos como delegação divina, absoluta e ilimitada. Surgiu no mesmo instante em que surgiram os primeiros Estados Absolutistas, governados por monarquias despóticas.

Conforme apontado por Dalmo de Abreu Dallari, a soberania é um dos elementos caracterizados do Estado, assim como o território e o povo (2010, p. 74). Portanto, ela nasce no momento em que também nasce 0 Estado, sendo que o conceito de soberania se consolida concomitante com a formação dos Estados M odernos no século XVI. 
O primeiro estudo realizado sobre o termo "soberania" teria sido "Les six livres de La République", de Jean Bodin, em 1576, em que o autor a define como "poder absoluto e perpétuo" de uma República (Estado), baseando-se na situação da monarquia na francesa daquela época (DALLARI, 2010, p. 76).

Jean Bodin teria sido um defensor do "direito divino dos reis" e, assim, em um Estado soberano, a vontade do rei seria expressão da vontade de Deus, portanto, inquestionável e absoluta.

Em 1762, com "O contrato social", Jean-Jacques Rousseau deu grande destaque ao estudo da soberania, concluindo por transferir sua titularidade da pessoa do governante para o povo, o que influenciou a Revolução Francesa com a ideia de que o poder do governante não pode ultrapassar os limites da vontade popular (DALLARI, 2010, p. 78).

A partir de então, vários filósofos começaram a questionar a divindade do governante e, para a criação dos Estados democráticos, chegou-se à conclusão de que a soberania do Estado provinha mesmo da vontade popular.

No plano interno de cada Estado, a soberania se expressa pelo poder de criar leis. Logo, soberana é a fonte da qual nascem as leis. Torna-se claro que, nos Estados Absolutistas, quem criava as leis era o monarca, chamado de soberano. Já nas democracias, soberano é o povo.

No plano internacional, soberania significa "autonomia" na medida em que 0 Estado é capaz de se autodeterminar, governando-se a si próprio, sem depender de outros e sem sofrer interferências não autorizadas por ele mesmo. Para René-Jean Dupuy, a soberania tem por corolário a igualdade dos Estados e, para Celso de Albuquerque M ello, a soberania é a grande característica do Estado enquanto pessoa internacional com capacidade de agir (DEL'OLM 0, 2009, p. 95).

Como características da soberania (fonte de criação das leis de um Estado capaz de se autodeterminar), cita-se a unidade, a indivisibilidade, a inalienabilidade e a imprescritibilidade. Ou seja, dentro do Estado há somente um poder supremo reconhecido pela ordem constitucional, que não se divide entre os entes da Federação, que não perece com o tempo nem é possível de ser transferido para outrem. Além disso, a soberania permite que o Estado seja livre para acolher ou não o direito internacional. 
Sinteticamente, pode-se dizer, então, que soberania é o poder do Estado de se autodeterminar, de definir suas próprias regras no âmbito de seu território e de ser independente em relação à comunidade internacional, que o reconhece e o respeita.

0 conceito de soberania foi e ainda é objeto de inúmeras obras teóricas de cientistas políticos, internacionalistas, estadistas, havendo concepções sob aspectos variados. Alguns a definem sob o ponto de vista político (como o fez Kelsen); outros, sob o ponto de vista jurídico; mas é sempre constante a noção de poder do Estado, estando a ele intrinsecamente ligado, pois somente este tem o poder e organizar seu governo, seus legisladores e sua jurisdição.

Apesar da construção do conceito de soberania tal como visto acima, muitos doutrinadores já previam ser ela limitada pelo direito divino, pelo direito natural e pelo direito das gentes. Atualmente, isto é inegável.

Em decorrência dos últimos acontecimentos na história e, reflexamente, nas sociedades democráticas ${ }^{2}$, o conceito de soberania começou a sofrer alterações, principalmente com a intensificação das relações internacionais comprometidas com a proteção dos direitos humanos. Continua sendo característica própria dos Estados, mas cedeu espaço ao Direito Internacional, visando a objetivos mais elevados, como a integração das nações para o progresso econômico, social ou humanitário.

\section{O novo Estado}

O autor Philip Bobbitt, na obra "A Guerra e a Paz na História Moderna", apresenta sua teoria de evolução dos Estados. Com o fim do feudalismo, as nações em formação se organizavam em reinos. Essas nações evoluíram para o surgimento do Estado Moderno. E este, por sua vez, está em transformação, frente aos últimos acontecimentos mundiais.

Bobbit afirma, então, que a "nação-Estado" evoluiu para o "Estado-nação", que, seria o Estado Moderno, o qual, por sua vez, está cedendo lugar ao que denomina de "Estado-mercado", que seria amplamente influenciado pelas empresas multinacionais (2003, p. 191-228).

\footnotetext{
${ }^{2}$ Com raras exceções, como os Estados Unidos da América que, de forma contraditória, ainda são resistentes à submissão integral aos tratados de direitos humanos, pois não se sujeitam à jurisdição de cortes internacionais.
} 
0 modelo de Estado-nação vincula a soberania às suas fronteiras territoriais. Significa dizer que, dentro de suas fronteiras (no âmbito interno), o Estado é supremo em relação ao seu direito e, fora (no âmbito internacional), tem o direito de reconhecimento pelos outros Estados na medida em que for capaz de defender suas fronteiras.

Ocorre que esse modelo de Estado enfrenta hoje vários desafios, conforme citados por Bobbitt (2003, p. 196): a) o reconhecimento dos direitos humanos como normas requerem a adesão de todos os Estados, independentemente de suas leis internas; b) armas nucleares e de destruição em massa fizeram com que a defesa simplesmente das fronteiras dos Estados se tornassem insuficientes; c) a proliferação de ameaças globais (danos ao meio ambiente; fome; migrações) transcendem as fronteiras do Estado; d) a expansão de um regime econômico mundial que ignora as fronteiras na movimentação de investimentos de capital, de maneira que os Estados se veem tolhidos na administração de seus problemas econômicos; e) a internet e os avanços na informática fizeram surgir uma nova comunicação global.

Em razão disso, a ordem constitucional do "Estado-nação" vem se transformando, já que está enfrentando uma crise de legitimidade. $E$, reflexamente, também a sociedade internacional vem sofrendo modificações.

Após a história provar o triunfo das democracias liberais frente ao fascismo e ao comunismo, os Estados encontram outras dificuldades para cumprir suas responsabilidades de promessa de fornecer segurança (paz), desenvolvimento econômico e social (bem estar).

Portanto, a tendência mundial é fazer surgir uma nova ordem constitucional nos Estados que reconheça os novos desafios da sociedade globalizada e afaste o conceito de soberania tal como previsto na formação dos Estados Modernos, priorizando a dignidade da pessoa humana.

Principalmente com a integração dos países em blocos, a exemplo da União Europeia e do Mercosul, a soberania mostra-se mais flexível, sendo relativa, divisível e mesmo delegável. Até mesmo a intervenção operacionalizada pela Organização das Nações Unidas passou a ser legítima em certos casos.

Do mesmo modo, face à proteção internacional dos direitos humanos, tornou-se legítima a intervenção na jurisdição doméstica dos Estados que desrespeitassem esses direitos, sem que isso significasse ameaça à soberania nacional. 
Em primeiro lugar, porque os organismos internacionais foram criados pelos próprios Estados engajados em causas maiores como a proteção dos direitos humanos, a busca da paz mundial, o progresso das relações econômicas, entre outras. Quando assim agem, os Estados transferem parte do exercício da soberania a estes organismos, sem renunciá-la.

Somente o Estado soberano pode aderir aos organismos internacionais e isso significa, em primeira análise, nítida manifestação do poder de se autodeterminar e da sua independência internacional, pois apenas pode transferir o exercício de um poder quem realmente o possua e sobre ele seja livre.

Com a internacionalização dos direitos humanos, há certo consenso de que a relativização da soberania estatal atua em benefício da efetivação desses direitos e justificase pelo bem comum universal (TAIAR, 2009, p. 306).

\section{A internacionalização dos direitos humanos}

Como visto, com a evolução histórica, também o conceito de soberania ganhou novas perspectivas. Após as atrocidades cometidas na Segunda Guerra M undial, os Estados perceberam a necessidade de manutenção da paz para a preservação da própria humanidade. Nesse sentido, criaram a Organização das Nações Unidas em 1945, e, em 1948, foi anunciada a Declaração Universal dos Direitos do Homem.

Neste novo cenário internacional que se formou, intensificaram o discurso sobre a universalização dos direitos humanos e a comunidade internacional passou a reconhecer que a proteção desses direitos constituía questão de interesse e preocupação global.

Conforme o pensamento de Hannah Arendt, após as barbáries cometidas por Hitler, se fez necessária a reconstrução dos direitos humanos, começando por reconhecer que o ser humano tem direito a ter direitos (LAFER, 1988).

Os Direitos Humanos foram declarados formalmente somente no século XVIII e surgiram com o reconhecimento dos direitos individuais. Apenas no século seguinte, os movimentos de classe consolidaram também os direitos sociais.

0 processo de internacionalização dos direitos humanos é fenômeno recente, se comparado à existência da humanidade. Possui seus próprios fundamentos e princípios, suas normas e seus mecanismos de supervisão. Somente a partir do final do século XX, a proteção 
da dignidade humana alcançou patamar de princípio fundamental, conferindo unidade ao sistema constitucional e sendo utilizado como princípio de hermenêutica das normas internacionais internalizadas pelos Estados.

O direito internacional público passou a reconhecer a pessoa humana como sujeito de direitos no plano internacional e os tratados multilaterais, como a Carta das Nações Unidas, passaram a espelhar a proteção internacional dos direitos humanos como pensamento contemporâneo dominante do mundo ocidental.

As relações internacionais se intensificaram e foi possível coexistir um sistema de proteção dos direitos fundamentais dentro de cada Estado com o sistema de proteção internacional dos direitos do homem.

Além do sistema global de proteção dos direitos humanos, foram criados os sistemas regionalizados, como o europeu, o africano e o interamericano, os quais coexistem e se completam.

O sistema interamericano de proteção dos direitos humanos, formado pela Organização dos Estados Americanos (OEA), tem como principal documento a Convenção Americana de Direitos Humanos, também conhecida por Pacto de San José da Costa Rica.

Este sistema, assim como o europeu, confere ao indivíduo personalidade jurídica internacional, isto é, o ser humano passou a ser sujeito de direito internacional, capaz de possuir e exigir direitos e obrigações de cunho internacional.

0 reconhecimento de que os seres humanos têm direitos sob o plano internacional implica a noção de que a negação desses mesmos direitos impõe, como resposta, a responsabilização internacional do Estado violador.

Com efeito, se, no exercício de sua soberania, os Estados aceitam as obrigações jurídicas decorrentes dos tratados de direitos humanos, passam então a se submeter à autoridade das instituições internacionais, no que se refere à tutela e fiscalização desses direitos em seu território (PIOVESAN, 2006, p. 9).

\section{A Constituição de 1988 e os direitos humanos}

A Constituição da República de 1988 demarcou o processo de democratização do Estado Brasileiro ao consolidar a ruptura com o regime autoritário militar, instalado em 1964, e ao consagrar os direitos e garantias fundamentais. Nas palavras de Ulysses 
Guimarães, Presidente da Assembleia Nacional Constituinte, ficou conhecida como a "Constituição Cidadã".

Esta Constituição, bem como outras constituições mais modernas, dispõe logo em seu primeiro artigo que a soberania é um dos fundamentos do Estado Democrático de Direito e afirma que "todo o poder emana do povo".

A partir de 1988, então, os direitos humanos ganharam relevo extraordinário, como jamais haviam tido anteriormente no Brasil. Esta Constituição reconheceu ainda que o princípio da dignidade humana confere sentido a todo o ordenamento jurídico, sendo seu ponto de partida e seu ponto de chegada. Foi por isso que veio expresso como fundamento da República (art. 1ํㅡ, inciso III), acompanhando todo o movimento constitucionalista PósSegunda Guerra, que consagrou a dignidade humana como superprincípio, a orientar tanto o direito interno como o direito internacional (PIOVESAN, 2006, p. 26).

Além dos direitos individuais, a Constituição de 1988 dispõe sobre os direitos sociais, políticos, econômicos e culturais, ampliando o rol de bens merecedores de tutela. Assim, o constituinte decidiu quais são os principais valores da sociedade brasileira e atribuiu a eles expressão jurídica, muitas vezes como metas a serem atingidas (normas programáticas).

$0 \S 10$ do artigo 50 da Constituição estabelece que as normas definidoras dos direitos e garantias fundamentais têm aplicação imediata, reforçando a imperatividade dessas normas, o que significa que independem de outras normas para terem efetividade.

Ante esta sistemática normativa constitucional, foi possível a ratificação de instrumentos internacionais de proteção dos direitos humanos pelo Estado brasileiro, como a Convenção Americana dos Direitos Humanos - o Pacto de San José da Costa Rica.

Estes tratados internacionais protegem especialmente os direitos dos homens, sem preocupação com as prerrogativas dos Estados. Ressalta-se ainda que a proteção internacional dos direitos humanos é complementar e subsidiária no Estado Brasileiro, com o propósito de suprir lacunas, pois já cabe ao sistema jurídico-normativo nacional a tarefa de promover esta proteção no plano interno.

Devido a este caráter subsidiário dos mecanismos de proteção internacional dos direitos humanos é que surgiu o princípio do esgotamento dos recursos internos, sendo até 
mesmo uma forma de respeito à soberania dos Estados e tolerância à capacidade de se autotutelar nessas questões (CANÇADO TRINDADE, 1991).

0 princípio do esgotamento dos recursos internos é constantemente alegado no contencioso internacional, perante as Organizações Internacionais, e por elas acolhido quando provado o engajamento estatal para a solução do litígio dentro do seu território.

No entanto, existindo realmente falha no sistema interno de proteção dos direitos humanos, pode haver a atuação dessas Organizações em prol da prevalência desses direitos, seja por recomendações ou mesmo por sentenças condenatórias, impondo obrigações internacionais, o que se deu após a criação das Cortes Internacionais.

Também foi reconhecida a possibilidade do indivíduo pleitear seus direitos na esfera internacional, até mesmo contra seu próprio Estado. É o que acontece no sistema regionalizado europeu e americano.

O Brasil é membro da Organização dos Estados Americanos e ratificou a Convenção Americana de Direitos Humanos, admitindo que qualquer cidadão brasileiro, que se sinta agredido pelo Estado por violação de um direito humano, possa denunciá-lo à Comissão Interamericana.

0 procedimento é relativamente simples, mas um dos requisitos para a aceitação da demanda pela Comissão é a observância do princípio do esgotamento dos recursos internos, pelo qual cada Estado tem poderes suficientes de criar mecanismos internos para proteger os direitos humanos em seu território.

Sendo assim, a conclusão é que os casos julgados pelo sistema interamericano de Direitos Humanos são demasiadamente graves e, por isso, merecem toda a atenção, uma vez que o Estado por si só não foi capaz de proteger um direito fundamental do cidadão, apesar de a Constituição da República Brasileira ser extensa na enunciação formal destes direitos.

\section{As cortes internacionais de proteção dos direitos humanos}

Atualmente, existem várias cortes internacionais com jurisdição sobre os Estadosparte que tutelam a observância das obrigações assumidas por meio de tratados.

No tema dos direitos humanos, o Brasil aderiu ao Tribunal Penal Internacional, que julga pessoas (e não Estados), e à Corte Interamericana de Direitos Humanos. 
A Corte Interamericana exerce jurisdição internacional e tem competência para julgar os Estados que a aceitaram expressamente por violações de direitos humanos consagrados na Convenção Americana de Direitos Humanos (Pacto de São José da Costa Rica) ou no próprio direito interno.

Em 1998, nosso país reconheceu a jurisdição da Corte Interamericana de Direitos Humanos e, em 2006, recebeu a sua primeira condenação, no Caso Ximenes Lopes, o que sugeriu a oportunidade de se pesquisar os mecanismos possíveis de cumprimento das sentenças proferidas por este órgão internacional.

Convém observar que as sentenças desta Corte são classificadas como sentenças internacionais e não se confundem com a sentença estrangeira, assim considerada aquela proferida por autoridade judiciária de outro país.

A homologação de sentenças estrangeiras decorre do princípio costumeiro internacional que desobriga o Estado a reconhecer decisõ es emanadas de outras soberanias. 0 procedimento de homologação da sentença estrangeira objetiva certificar que ela não ofende a soberania nacional nem a ordem pública interna.

Diferente é a situação da sentença internacional. Tendo em vista que o tribunal internacional profere sentenças por força de um tratado assinado e ratificado pelo Estadoparte, em que este transferiu parcela do seu poder de imperium quando se sujeitou à jurisdição daquele, não há que se falar em desrespeito à autonomia e à exclusividade da jurisdição nacional ao acatar tal decisão sem necessidade de homologação.

Até a presente data, já houve cinco sentenças proferidas em casos brasileiros na Corte Interamericana, sendo quatro condenações ${ }^{3}$.

Geralmente, as sentenças da Corte valem-se do conceito de reparação integral das vítimas, o que abrange indenizações pecuniárias e também medidas a serem adotadas pelo Estado condenado para prevenir novas violações de direitos humanos, dentre outras obrigações de fazer.

Com a condenação, os Estados devem se organizar para o cumprimento da sentença. Alguns Estados americanos possuem legislação específica disciplinando sobre o

\footnotetext{
${ }^{3}$ O Brasil foi condenado pela Corte Interamericana no Caso Ximenes Lopes, Caso Escher, Caso Sétimo Garibaldi e Caso Gomes Lund.
} 
modo de cumprimento dessas decisões, como a Colômbia ${ }^{4}$. Mas o Brasil ainda não possui essa legislação (enabling legislation), apesar de haver alguns projetos de lei tramitando no Congresso Nacional.

0 artigo 20 do Pacto de San José dispõe que cada Estado-parte deve adaptar sua legislação interna para fins de cumprir com as obrigações internacionais assumidas naquele tratado. Também 0 artigo 68 do mesmo instrumento normativo prevê que cada Estadoparte pode se valer da sua normatividade interna para dar cumprimento às sentenças da Corte Interamericana, podendo, inclusive, aplicar as mesmas regras de pagamento das indenizações feitas pelo Estado no direito interno.

Como se não bastasse, 0 artigo 27 da Conven ção de Viena, o "tratado dos tratados", disciplina que nenhum Estado pode invocar seu direito interno para descumprir ou cumprir imperfeitamente um tratado internacional ao qual tenha aderido espontaneamente.

Logo, não há justificativa para o não cumprimento de uma obrigação imposta pela sentença internacional.

O cumprimento dessas decisões internacionais é exercício da cooperação jurídica internacional vertical (que se dá entre um Estado e um órgão internacional, enquanto a cooperação jurídica internacional horizontal ocorre entre dois Estados).

A cooperação jurídica internacional é um fenômeno que vem ganhando espaço na atualidade por causa dos vários fatores já elencados acima sobre a nova estrutura dos Estados e suas soberanias.

Portanto, não basta aderir ao tratado internacional de direitos humanos e formalmente se vincular ao sistema interamericano. É preciso implementá-lo e respeitá-lo na prática da atuação governamental.

A Constituição Brasileira de 1988 prevê a prevalência dos direitos humanos como princípio a orientar nosso Estado nas relações internacionais. Esta norma é dotada de eficácia e deve ser cumprida. Igualmente, a internalização da Convenção Americana de direitos humanos e a aceitação da jurisdição da Corte Interamericana são normas dotadas de força vinculante, seja no âmbito interno, seja no âmbito internacional.

Outra solução não há, portanto, que a obediência às sentenças da Corte Interamericana. Não que esta seja uma tarefa fácil.

\footnotetext{
${ }^{4}$ Lei $n^{\circ} 288 / 96$
} 
Da análise das resoluções de supervisão de sentença emitidas pela Corte, verifica-se que os países que aceitaram sua jurisdição encontram dificuldades para o cumprimento das obrigações impostas nas condenações.

Aliás, as obrigações não pecuniárias têm sido menos cumpridas pelos Estados condenados, principalmente por não existir um consenso sobre qual o procedimento a ser adotado, por exemplo, quando a Corte determina a implementação de determinadas políticas públicas visando à efetivação de direitos humanos (ex: políticas públicas na área da saúde, políticas de reforma agrária, políticas de implementação de direitos trabalhistas, etc) (MAEOKA, 2008). Ou seja, tem sido mais simples o pagamento de indenizações pecuniárias do que a adoção de medidas políticas ou consistentes em obrigações de fazer.

Realmente, há sentenças da Corte Interamericana que condenam o Estado exigindo que o mesmo adote medidas legislativas, administrativas e mesmo judiciárias objetivando à concretização dos direitos humanos, tudo com base no Pacto de San José. A Corte tem feito um controle de convencionalidade (tendo como parâmetro a Convenção Americana) dos atos do Estado-parte acusado.

Ainda que não se tenha atualmente um método perfeito de internalização das sentenças internacionais, é preciso escolher aquele que encontre o equilíbrio entre 0 sistema jurídico interno e o internacional para o cumprimento dessas decisões.

As dificuldades existem também no âmbito interno, quando o Poder Judiciário nacional condena o próprio Estado à realização de determinada medida para a implementação de direitos humanos. Os entraves se apresentam, principalmente, em razão dos princípios da separação dos poderes (pelo qual o Poder Judiciário não pode se substituir ao Executivo nem ao Legislativo, invadindo a esfera de competência de cada um deles), da discricionariedade administrativa (pelo qual a função de administrar é típica do Executivo e a ele compete a escolha sobre qual demanda social atender primeiramente) e das restrições orçamentárias (pelo qual o orçamento do Estado é limitado e insuficiente para atender a todas as demandas sociais).

Quando a Corte Interamericana condena um Estado-parte no mesmo sentido, impondo a ele a realização de determinada medida para a concretização de direitos humanos, é de se considerar esta sentença equiparada a uma sentença nacional, que será 
cumprida dentro dos limites da proporcionalidade e da razoabilidade da condenação, observando a realidade estrutural e orçamentária existente.

É certo que as obrigações não-pecuniárias impostas aos Estados têm como objetivo a punição e a prevenção de novas violações, com a pretensão de eliminar as deficiências da rede interna de proteção dos direitos humanos.

Portanto, a eficácia do sistema interamericano de proteção dos direitos humanos está diretamente vinculada ao êxito da execução dessas decisões da Corte. A Justiça internacional somente cumprirá efetivamente seu papel de promover os direitos humanos no momento em que as suas decisões forem acatadas de boa-fé e com lealdade pelos Estados-parte (M AEOKA, 2008, p. 94).

\section{Considerações finais}

Foi visto que um novo conceito de soberania surgiu frente às mudanças sociais e econômicas dos últimos tempos, em que prevalece a dignidade humana nas relações internacionais.

A Constituição Brasileira de 1988 representou um grande avanço na proteção dos direitos humanos e seu artigo 4을 inciso II, possibilitou a abertura do sistema jurídico interno para o sistema internacional de proteção desses direitos.

Nesse sentido, o Brasil aderiu à jurisdição da Corte Interamericana de Direitos Humanos e tem participado do contencioso internacional, havendo recente jurisprudência em seu desfavor.

As sentenças condenatórias da Corte Interamericana prevêem o pagamento de indenização às vítimas e também a adoção de outras medidas pelo Estado condenado, sendo que 0 pagamento das indenizações tem sido a parte menos complexa de ser executada, havendo dificuldade de cumprimento das decisões no tocante à adoção pelos Estados das medidas de não-repetição (políticas preventivas de futuras violações de direitos humanos).

Em razão da legitimidade da jurisdição da Corte Interamericana, deve-se buscar soluções para o cumprimento de suas decisões de forma adequada ao nosso ordenamento jurídico vigente. 
O cumprimento das sentenças da Corte Interamericana de Direitos Humanos é a demonstração de respeito a estes direitos, aos tratados internacionais que os declararam e à própria efetivação da democracia brasileira.

O cenário mundial que vem se formando tende a requerer cada vez mais a ampliação da cooperação jurídica internacional e o Brasil deve estar preparado para enfrentar estes novos desafios.

\section{Referências}

BONAVIDES, Paulo. Do estado liberal ao estado social. 7aㅡ ed., São Paulo: Malheiros, 1997.

BOBBIO, Norbeto. Estado, governo, sociedade: para uma teoria geral da política. $11^{\mathfrak{a}}$ ed., Rio de Janeiro: Paz e Terra, 2004.

BOBBITT, Philip. A Guerra e a Paz na História M oderna: o impacto dos grandes conflitos e da política na formulação das nações. Tradução de Cristiana Serra; Rioa de Janeiro: Campus, 2003.

CANÇADO TRINDADE, Antônio Augusto. A proteção Internacional dos Direitos Humanos: Fundamentos Jurídicos e Instrumentais Básicos. São Paulo: Saraiva, 1991.

CANOTILHO, José Joaquim Gomes. Constituição dirigente e vinculação do legislador. $2^{a}$ ed., Coimbra: Coimbra Editora, 2001.

COM PARATO, Fábio Konder. A afirmação histórica dos direitos humanos. São Paulo: Saraiva, 1999.

CONVENÇÃO AM ERICANA DE DIREITOS HUM ANOS. Disponível em: বttps://www.cidh.oas.org/Basicos/Portugues/c.Convencao_Americana.htm $>$. Acesso em 07 fev. 2011.

CORTE EUROPÉIA DE DIREITOS HUM ANOS. Disponível em: «ttp:// www.echr.coe.int>. Acesso em 07 fev. 2011

DALLARI, Dalmo de Abreu. Elementos de Teoria Geral do Estado. 29a ed.. São Paulo: Saraiva, 2010.

. O futuro do Estado. 2a ed. rev. e atual.. São Paulo: Saraiva, 2007.

DALLARI, Pedro. Normas Internacionais de Direitos Humanos e a Jurisdição Nacional. Revista Especial do Tribunal Regional da 3ạ Região: Seminário Incorporação dos Tratados Internacionais de Proteção dos Direitos Humanos no Direito Brasileiro, São Paulo: 1997, pp. 25-38. 
DEL'OLM O, Florisbal de Souza. Curso de Direito Internacional Público. 4a ed. Rio de Janeiro: Forense, 2009, p. 95.

DOLINGER, Jacob. As soluções da Suprema Corte Brasileira para os Conflitos entre o Direito Interno e o Direito Internacional: um exercício de ecletismo. Revista Forense: Rio de Janeiro, vol. 334, 1996, pp. 71-107.

ESTATUTO DA CORTE INTERAM ERICANA DE DIREITOS HUM ANOS. Disponível em: «ttp://www.corteidh.or.cr/Regulamento.pdf>. Acesso em 07 fev. 2011.

FREITAS, Riva Sobrado de. Aspectos do estado contemporâneo e desafios na formulação das políticas sociais. Sequência - Estudos jurídicos e políticos - Revista do Curso de Pósgraduação em Direito da UFSC, ano XXVII, dez/2008, p. 31-46.

HABERM AS, Jürgen. Direito e democracia entre facticidade e validade. vol. 1, Rio de Janeiro: Tempo Brasileiro, 2003.

. Sobre a legitimação pelos direitos humanos. In: M ERLE, Jean-Christophe e M OREIRA, Luiz (org.). Direito e Legitimidade, São Paulo: Landy Editora, 2003.

LAFER, Celso. A reconstrução dos direitos humanos: um diálogo com o pensamento de Hannah Arendt. São Paulo: Companhia das Letras, 1988.

M AEOKA, Érika. $O$ acesso à justiça e a proteção dos direitos humanos: os desafios à exigibilidade das sentenças da Corte Interamericana. Trabalho publicado nos Anais do XVII Congresso Nacional do CONPEDI, realizado em Brasília-DF, em novembro de 2008.

MIRANDA, Jorge. Constituição e cidadania. Coimbra: Coimbra Editora, 2003.

M ORAES, Alexandre de. Direito Constitucional. 15ạ ed., São Paulo: Editora Atlas, 2004.

PIOVESAN, Flávia. Direitos Humanos e o Direito Constitucional Internacional, 7ạ ed., São Paulo: Saraiva, 2006.

- Justiciabilidade dos direitos sociais e econômicos: desafios e perspectivas. In:

CANOTILHO, J.J. Gomes et al (coord.). Direitos Fundamentais Sociais, São Paulo: Saraiva, 2010, p. 53-69.

RAM OS, André de Carvalho. Processo internacional de direitos humanos: análise dos sistemas de apuração de violações de direitos humanos e implementação das decisões no Brasil. Rio de Janeiro: Editora Renovar, 2002.

SILVA, José Afonso da. Poder constituinte e poder popular. São Paulo: M alheiros, 2002. 
TAIAR, Rogério. Direito Internacional dos Direitos Humanos: uma discussão sobre a relativização da soberania face à efetivação da proteção internacional dos direitos humanos. Tese de doutorado, 2009.

Artigo recebido em: 14 de junho de 2011 Artigo aprovado em: 21 de agosto de 2011 